\title{
Recombinant human thyroid stimulating hormone does not acutely change serum osteoprotegerin and soluble receptor activator of nuclear factor-kB ligand in patients under evaluation for differentiated thyroid carcinoma*
}

\author{
Massimo Giusti, ${ }^{1}$ Francesca Cecoli, ${ }^{1}$ Carla Ghiara, ${ }^{2}$ Alessandro Rubinacci, ${ }^{3}$ \\ Isabella Villa, ${ }^{3}$ Domenico Cavallero, ${ }^{1}$ Laura Mazzuoli, ${ }^{1}$ Michele Mussap, ${ }^{2}$ \\ Roberto Lanzi, ${ }^{3}$ Francesco Minuto ${ }^{1}$
}

${ }^{1}$ UO Clinica Endocrinologia and ${ }^{2}$ UO Laboratorio Analisi, ${ }^{3}$ Azienda Ospedale Università "San Martino", Genova and UO Diabetologia, Endocrinologia e Malattie Metaboliche, Istituto Scientifico San Raffaele, Milano, Italy

\begin{abstract}
OBJECTIVE: Some extra-thyroid actions of thyroid stimulating hormone (TSH), such as an in vitro action on bone, have been described. Our aim was to evaluate in vivo the acute effect of a recombinant human TSH (rhTSH)-induced TSH surge on Osteoprotegerin (OPG) and receptor activator of the nuclear factor- $x$ B (RANK-L) levels in patients under levo-thyroxine (L-T4) therapy. DESIGN: 24 patients with differentiated thyroid carcinoma (DTC) were studied. Standard rhTSH testing was performed. OPG, RANK-L, TSH, thyroid hormones, thyroglobulin and several parameters of bone metabolism were evaluated. RESULTS: Baseline OPG and RANK-L levels were in the range of our reference population. An inverse correlation between OPG and spinal $Z$-score $(p=0.029)$ and between $R A N K-L$ and age $(p=0.018)$ or urinary calcium/creatinine ratio $(p=0.011)$ was detected. After rhTSH administration, a significant $(p<0.001)$ increase in TSH was found. No significant increase in OPG or RANK-L levels after rhTSH was observed. No correlation was detected between TSH peak value after rhTSH and maximal percentage change in OPG or RANK-L. A slight increase in urinary cross-links after rhTSH was found. CONCLUSIONS: In a small group of subjects with a history of DTC on LT4 regimen, our study did not support an acute direct effect of TSH on OPG and RANK-L.
\end{abstract}

Key words: Differentiated thyroid carcinoma, Osteoprotegerin, RANK-L, rhTSH

Address for correspondence:

Massimo Giusti, Dipartimento di Scienze Endocrinologiche e Metaboliche. UO Clinica Endocrinologica. Ospedale-Università "San Martino" Genova. Viale Benedetto XV, 6, I-16100 Genoa, Italy, Tel.: +39/010-353-7953, Fax +39/010-353-8977, e-mail: magius@unige.it

Received 14-12-06, Revised 10-07-07, Accepted 05-08-07

*The present paper was presented in part at the XXVI Giornate Endocrinologiche Pisane, Pisa, Italy, June 8-10, 2006 


\section{INTRODUCTION}

Bone homeostasis is the result of coordinated interactions among local and systemic factors that regulate the genesis, activity and survival of osteoblasts and osteoclasts. Recent experimental studies have shown that osteoclastogenesis is mainly determined by an endogenous cytokine system, which regulates the maturation of preosteoclasts into active osteoclasts. ${ }^{1-4}$ Osteoprotegerin $(\mathrm{OPG})^{1,2}$ and receptor activator of the nuclear factor-kB (RANK)/RANKligand (RANK-L) system ${ }^{3,4}$ are now thought to explain the mechanisms of the cross-talk between osteoblasts and osteoclasts. OPG is considered to be a soluble receptor secreted by several types of cells, including osteoblasts $^{1,5}$. Thyroid follicular cells also seem to produce OPG, and this synthesis may be modulated by thyroid autoimmunity. ${ }^{6}$ OPG works as a decoy receptor for RANK-L, thereby acting as an inhibitor of osteoclastogenesis. ${ }^{7}$ Many cell types, including osteoblasts, express RANK-L. ${ }^{8}$ The cell-bound form of RANK-L is the most common, although a soluble form exists, which is produced by the cleavage of an ectodomain truncated by a protease and primary secretion from cells. ${ }^{4,7}$ By binding to RANK, RANK-L promotes osteoclast differentiation, activation, survival and adherence to bone surface. ${ }^{9,10}$

In humans, recent studies have indicated that serum OPG can be regarded as a marker of cardiovascular risk ${ }^{11}$ and that the OPG/RANK/RANK-L system is involved in several diseases characterized by bone loss, such as osteoporosis - either in the elderly or glucocorticoid-induced ${ }^{12}$ - bone metastasis, ${ }^{13}$ and rheumatoid arthritis. ${ }^{14}$ On the other hand, a pilot study in which OPG was administered to post-menopausal women showed that it might have a therapeutic role in reducing bone loss. ${ }^{15}$ Overt hyperthyroidism is another condition in which bone loss occurs. ${ }^{16}$ In patients with hyperthyroidism, an increase in serum OPG levels has been reported which can be reversed by treating the disease, even in the presence of persistent microstructural deterioration of bone as determined by ultrasonography. ${ }^{17}$ An increase in serum OPG has also been found in sub-clinical and overt hypothyroidism before substitutive therapy, probably as a consequence of vascular damage. ${ }^{18}$ Recently, in patients operated on for differentiated thyroid carcinomas (DTC) and on long-term suppres- sive levo-thyroxine (L-T4) treatment, an increase in serum OPG in comparison with age-matched normal subjects has been reported. ${ }^{19}$ Finally, in a crosssectional study performed on a random sample of community-dwelling adults, serum OPG levels were associated with a profile of bone turnover markers favouring bone formation, suggesting that OPG may be protective against age-related bone loss. ${ }^{20}$

To our knowledge, very few data are available on soluble RANK-L in humans, owing to technical problems in the assay. ${ }^{8}$ In a group of endurance runners, a significant decrease in RANK-L was observed during running, the extent of which seems to be correlated with the distance covered. ${ }^{21}$ Moreover, reduced soluble RANK-L levels in DTC in comparison with healthy euthyroid age-matched controls have recently been reported. ${ }^{19}$

Our knowledge of the OPG/RANK/RANK-L system in humans is still scant. The future role of its evaluation in clinical practice remains to be clarified, ${ }^{8}$ and the controversial extra-thyroid action of TSH on bone must be considered within this scenario. ${ }^{22}$ TSH might exert a direct role in bone remodelling by interacting with specific receptors expressed on bone cells. ${ }^{22}$ The increase in serum TSH levels produced by recombinant human TSH (rhTSH) administration can be exploited in an in vivo model to evaluate the possible acute effect exerted by TSH on the OPG/ RANK/RANK-L system. To our knowledge, only one paper has been published on this topic. Mazziotti et $\mathrm{al}^{23}$ showed that the acute increase in TSH levels in DTC patients after rhTSH is accompanied by a decrease in serum C-telopeptide of type 1 collagen and an increase in bone-alkaline phosphatase, without any significant effect on circulating OPG concentration.

Our study was scheduled to further evaluate, in a well characterized group of DTC patients, the acute effect of rhTSH on OPG and to extend evaluations to soluble RANK-L and urinary products of bone collagen metabolism.

\section{MATERIALS AND METHODS}

\section{Subjects}

The study was conducted during scheduled yearly 
rhTSH testing of 24 outpatients (mean age \pm SD: $50.7 \pm 12.2$ years) with a history of stage 1-4 DTC. Pertinent clinical data on the subjects studied are reported in Table 1 . The majority of patients were pre-menopausal $(\mathrm{n}=7 ; 38.0 \pm 7.5$ years $)$ and post-menopausal $(\mathrm{n}=10 ; 59.6 \pm 6.2$ years $)$ females. Our study group also included 7 males (mean age $50.7 \pm 11.6$ years). DTC had been diagnosed 1 to 25 years prior to the study (median 3 years); total thyroid ablation by near-total thyroidectomy and subsequent radioiodine therapy was our standard treatment for all subjects. Histology revealed papillary cancer, follicular variant of papillary cancer, follicular cancer and insular cancer in 18, 4, 1 and 1 subjects, respectively (Table 1). All subjects were on an L-T4 regimen at the time of examination. L-T4 therapy was TSH-suppressive in the majority of patients. In 6 patients (cases 1, 7, 12, 20-22) rhTSH testing was performed 2 months after their scheduled $\mathrm{L}-\mathrm{T} 4$ regimen had been reduced by about $25 \%$, in accordance with our protocol of sensitizing thyroid to rhTSH administration. ${ }^{24}$ Cases 23 and 24 did not show suppressed TSH despite receiving high L-T4 doses, probably because of inadequate absorption of the drug (Table 1).

Table 1. Pertinent clinical and hormonal data of the subjects studied.

\begin{tabular}{|c|c|c|c|c|c|c|c|c|c|c|}
\hline Case & $\begin{array}{l}\text { Age } \\
\text { yrs }\end{array}$ & $\begin{array}{c}\text { Age at diagnosis } \\
\text { yrs }\end{array}$ & $\begin{array}{c}\text { Histology } \\
\text { (1) }\end{array}$ & $\begin{array}{l}\text { Stage } \\
(2)\end{array}$ & $\begin{array}{c}\mathrm{BMI} \\
\mathrm{kg} / \mathrm{m}^{2}\end{array}$ & $\begin{array}{c}\mathrm{L}-\mathrm{T4} \\
\mu \mathrm{g} / \text { week }\end{array}$ & $\begin{array}{c}\text { FT3 } \\
\mathrm{pmol} / \mathrm{l}\end{array}$ & $\begin{array}{c}\text { FT4 } \\
\mathrm{pmol} / \mathrm{l}\end{array}$ & $\begin{array}{c}\text { TSH } \\
\mathrm{mIU} / \mathrm{l}\end{array}$ & $\begin{array}{c}\mathrm{Tg} \\
\mu \mathrm{g} / \mathrm{l}\end{array}$ \\
\hline \multicolumn{11}{|c|}{ Pre-menopausal women } \\
\hline 1 & 28 & 18 & PTC & 1 & 20.7 & 700 & 3.5 & 16.3 & 1.52 & $<0.5$ \\
\hline 2 & 31 & 28 & PTC & 1 & 22.1 & 875 & 7.1 & 29.6 & $<0.03$ & $<0.5$ \\
\hline 3 & 33 & 29 & F var PTC & 1 & 19.2 & 850 & 4.8 & 17.4 & 0.03 & $<0.5$ \\
\hline 4 & 40 & 38 & PTC & 1 & 18.5 & 1050 & 5.4 & 22.5 & 0.12 & $<0.5$ \\
\hline 5 & 42 & 41 & PTC & 1 & 25.7 & 1100 & 5.5 & 28.6 & 0.10 & $<0.5$ \\
\hline 6 & 43 & 18 & PTC & 1 & 35.6 & 1212 & 4.6 & 22.4 & $<0.03$ & $<0.5$ \\
\hline 7 & 49 & 45 & PTC & 4 & 35.1 & 700 & 4.4 & 14.3 & 1.64 & $<0.5$ \\
\hline \multicolumn{11}{|c|}{ Post-menopausal women } \\
\hline 8 & 53 & 51 & PTC & 2 & 27.7 & 875 & 3.4 & 15.1 & 0.60 & $<0.5$ \\
\hline 9 & 53 & 44 & F var PTC & 2 & 26.8 & 700 & 3.1 & 19.8 & 0.21 & $<0.5$ \\
\hline 10 & 55 & 54 & F var PTC & 2 & 24.8 & 787 & 3.7 & 23.8 & 0.92 & $<0.5$ \\
\hline 11 & 57 & 56 & F var PTC & 1 & 22.9 & 1000 & 5.2 & 18.8 & 1.13 & 0.5 \\
\hline 12 & 58 & 56 & PTC & 1 & 25.6 & 700 & 3.1 & 13.2 & 2.31 & $<0.5$ \\
\hline 13 & 58 & 54 & PTC & 2 & 26.9 & 700 & 4.1 & 16.9 & 0.10 & $<0.5$ \\
\hline 14 & 58 & 46 & PTC & 2 & 25.9 & 875 & 4.4 & 19.0 & 0.05 & $<0.5$ \\
\hline 15 & 65 & 62 & PTC & 1 & 27.6 & 1050 & 4.3 & 21.9 & $<0.03$ & $<0.5$ \\
\hline 16 & 68 & 66 & PTC & 1 & 36.9 & 1050 & 5.2 & 30.0 & $<0.03$ & 0.5 \\
\hline 17 & 71 & 68 & Insular & 3 & 32.4 & 875 & 4.6 & 21.4 & 0.12 & $<0.5$ \\
\hline \multicolumn{11}{|l|}{ Males } \\
\hline 18 & 32 & 30 & FTC & 1 & 22.2 & 925 & 6.0 & 25.2 & 0.05 & 0.5 \\
\hline 19 & 38 & 35 & PTC & 1 & 29.4 & 1500 & 3.4 & 14.3 & 0.62 & $<0.5$ \\
\hline 20 & 50 & 47 & PTC & 2 & 34.1 & 350 & 3.1 & 14.9 & 3.90 & $<0.5$ \\
\hline 21 & 54 & 50 & PTC & 3 & 23.3 & 525 & 5.1 & 14.4 & 2.83 & $<0.5$ \\
\hline 22 & 58 & 56 & PTC & 3 & 25.6 & 700 & 3.1 & 13.2 & 2.31 & $<0.5$ \\
\hline 23 & 61 & 58 & PTC & 1 & 26.2 & 925 & 4.1 & 22.1 & 9.34 & $<0.5$ \\
\hline 24 & 62 & 60 & PTC & 1 & 25.6 & 1100 & 4.3 & 30.4 & 2.85 & $<0.5$ \\
\hline
\end{tabular}

${ }^{1} \mathrm{PTC}=$ papillary thyroid carcinoma, $\mathrm{F}$ var PTC $=$ follicular variant of PTC, FTC $=$ follicular thyroid carcinoma.

Thyroid staging was evaluated according to the TNM 2002 classification. 


\section{Protocol}

All patients underwent clinical examination and, specifically, neck palpation and body mass index (BMI) evaluation. Pharmacological history was recorded and ultrasonography was carried out. Following overnight fasting and, after $12 \mathrm{hrs}$ abstinence from smoking, a blood sample was obtained for serum OPG, RANK$\mathrm{L}$, thyroid hormones, TSH and thyroglobulin (Tg) determination. Fasting urine spot was collected for the determination of urinary cross-links: pyridinoline (PD)/creatinine ratio and deoxpyridinoline (DPD)/ creatinine ratio. Samples were collected before and 3, 6 and 9 days after rhTSH administration. Patients received two consecutive daily (days 1 and 2) i.m. doses of rhTSH (0.9; Genzyme Co., Cambridge, MA, USA). Baseline (day 0) serum PTH, osteocalcin, total calcium, phosphorus, creatinine, alkaline phosphatase (ALP) and urinary 24-h calcium, calcium/creatinine ratio and hydroxyproline (HP)/creatinine ratio were also evaluated. Anti-Tg autoantibody (TgAb) was evaluated to identify sera in which a Tg-recovery test was necessary to obtain reliable Tg values. ${ }^{25}$ Serum and urine were frozen at $-70^{\circ} \mathrm{C}$ before assays, which were performed within 6 months of collection. Except for cases 3 and 18, bone mineral density (BMD; gr/ $\mathrm{cm}^{2}$ ) of four regions of the spine (lumbar vertebrae L1-L4) and total femur was also measured in the antero-posterior projection by dual energy X-ray absorptiometry (DXA).

\section{Assays}

Serum OPG and RANK-L were assayed by means of a commercial ELISA sandwich (Biomedica Medizinprodukte, Wien, Austria). Samples from the same subject were evaluated in duplicate in the same assay. In our laboratory, in a cohort of 80 DTC patients (68 females and 12 males; age range 27-81 years) and 55 subjects with a history of thyroid surgery for benign thyroid disease (51 females and 4 males; age range 39-73 years), the median value observed for OPG was $2.4 \mathrm{pmol} / \mathrm{l}$ (range $0.6-5.7 \mathrm{pmol} / \mathrm{l}$ ) and $2.8 \mathrm{pmol} / \mathrm{l}$ (range $1.0-5.9 \mathrm{pmol} / \mathrm{l})$, respectively. In the same cohorts of subjects, soluble RANK-L presented a median value of $0.24 \mathrm{pmol} / \mathrm{l}$ (range $<0.08-1.28 \mathrm{pmol} / \mathrm{l}$ ) and 0.25 $\mathrm{pmol} / \mathrm{l}$ (range $<0.08-0.91 \mathrm{pmol} / \mathrm{l})$, respectively. In our laboratory the detection limits were $0.1 \mathrm{pmol} / 1$ and $0.08 \mathrm{pmol} / \mathrm{l}$ for OPG and RANK-L. Intra-assay variation expressed as coefficients of variation $(\mathrm{CV})$ was $5 \%$ for OPG and 3\% for RANK-L. Serum Tg was assayed by chemiluminescence immunoassay (Roche Diagnostics, Mannheim, Germany). Assays were standardized against the certified reference for human Tg (CRM 457) of the Community Bureau of References of the European Commission. The lower analytic limit and functional sensitivity of the method are $0.1 \mu \mathrm{g} / \mathrm{l}$ and $0.5 \mu \mathrm{g} / \mathrm{l}$, respectively. In our laboratory the intra-assay CVs were $5 \%$ and $8 \%$. On the basis of the functional sensitivity of the methods, we selected $0.5 \mu \mathrm{g} / \mathrm{l}$ as the cut-off value to discriminate undetectable from detectable Tg levels. Tg-antibodies were measured by commercial assay (Dia Sorin, Saluggia, Italy). A concentration of $100 \mathrm{mIU} / \mathrm{lgG}$ to $\mathrm{Tg}$ was taken as the cut-off value. Serum free-thyroid hormones and TSH were measured by ultra-sensitive chemiluminescence immunoassay (Roche Diagnostics). Normal ranges are 0.3-4.2 mIU/l for TSH, 3.9-6.8 $\mathrm{pmol} / \mathrm{l}$ and 12.0-22.0 pmol/l for free-T3 (FT3) and free-T4 (FT4), respectively. PTH was analysed by chemiluminescence immunoassay (Immulite 2000; Diagnostic Products Co., San Juan Capistrano, CA, USA). Intra-assay CV was $4 \%$ and assay sensitivity was $5 \mathrm{ng} / \mathrm{l}$. In our laboratory the normal range of PTH is $15-65 \mathrm{ng} / \mathrm{l}$. Osteocalcin was measured by chemiluminescence immunoassay (Nichols Advantage, San Juan Capistrano, CA, USA). The normal range is 0.5-7.0 $\mu \mathrm{g} / \mathrm{l}$ and the intra-assay CV was $5 \%$. Serum creatinine (normal range: $44-115 \mu \mathrm{mol} / \mathrm{l}$ ), calcium (2.12-2.70 mmol/l), phosphorus (0.80-1.45 mmol/l), and total alkaline phosphatase (ALP; 98-280 U/l) were determined by Modular Roche. Urinary calcium concentration was measured by standard procedures in 24-h samples (normal range: $1.25-7.50 \mathrm{mmol} / 24 \mathrm{~h}$ ), or in spot urine samples and expressed as the molar ratio to creatinine (normal range: 0.0-0.2). Urinary HP, PD and DPD were measured by high-performance liquid chromatography (HPLC, BioRad, Milan, Italy). Methods were optimised by using the CDC (Centre for Disease Control and Prevention, Atlanta, GA, USA) standards. Data are expressed as the molar ratio to creatinine. In our laboratory normal ranges were 6-22, 25-63 and 5-14, respectively. CVs were $4 \%$ for $\mathrm{HP}, 6 \%$ for PD and $7 \%$ for PDP. BMD was evaluated by DXA instruments (Hologic QDR 1500 and QDR 4500, Waltham, MA, USA). The so- 
called standard deviation scores, which indicate the deviation from normal values, were calculated by means of the following equations: $\mathrm{T}$ score $=\mathrm{BMD}$ measured - BMD young normal population/SD; Z score $=$ BMD measured - BMD sex- and age-matched population/SD.

\section{Statistical analysis}

Data were analysed by means of the Prism 4.0 software (GraphPad Software, San Diego, CA, USA). Changes in OPG, RANK-L, TSH, Tg, FT3, FT4, and cross-links under rhTSH testing were analysed by means of the non-parametric Kruskal-Wallis test, followed, when appropriate, by Dunn's multiple comparison test. Baseline data were compared with those of the reference population by Mann-Whitney test. Correlation analyses between variables were carried out by Spearman correlation. All values quoted are means \pm SEM. Data below the functional sensitivity of the assay were analysed for statistical purposes by means of the functional sensitivity value. Exact $\mathrm{p}$ values ranging from 0.200 to 0.001 are reported. Significance was taken as $p<0.050$. At least 1 year after primary therapies, the best predictor of cure in DTC patients was considered to be an undetectable $\mathrm{Tg}(<0.5 \mu \mathrm{g} / \mathrm{l})$ level after rhTSH testing, combined with negative neck ultrasonography. ${ }^{26,27}$ According to the WHO classification system, osteoporosis was defined as T-scores lower than 2.5 at any of the major measurement sites. ${ }^{28}$

\section{RESULTS}

L-T4 dosages ranged from 350 to $1500 \mu \mathrm{g} /$ week (median $875 \mu \mathrm{g} /$ week; 880.2 $\pm 48.7 \mu \mathrm{g} /$ week). Free-T3 was in the normal range in all subjects, while 9 out of 24 subjects showed slight hyperthyroxinemia at the time of rhTSH testing (Table 1). Under L-T4, TSH ranged from undetectable $(<0.03 \mathrm{mU} / \mathrm{l})$ to $9.34 \mathrm{mU} / \mathrm{l}$ (median $0.40 \mathrm{mU} / \mathrm{l} ; 0.53 \pm 0.03 \mathrm{mU} / \mathrm{l}$ ). The inverse correlation between L-T4 dosage and $\mathrm{TSH}$ suppression was significant $(\mathrm{rS}-0.41 ; \mathrm{p}=0.044)$. Undetectable baseline Tg levels were found in all patients (Table 1). Baseline OPG (median $2.2 \mathrm{pmol} / \mathrm{l} ; 2.2 \pm 0.2 \mathrm{pmol} / \mathrm{l}$ ) and RANK-L (median $0.24 \mathrm{pmol} / \mathrm{l} ; 0.26 \pm 0.04 \mathrm{pmol} / \mathrm{l}$ ) levels were in the range of our cohort of reference subjects who had undergone surgery for malignant or benign thyroid disease (Table 2). Baseline OPG has shown only a significant inverse correlation with spinal $\mathrm{Z}$-score ( $\mathrm{rS}-0.46, \mathrm{p}=0.029)$, but no other significant correlation was observed. By contrast, soluble RANK$\mathrm{L}$ was negatively related with age $(\mathrm{rS}-0.48, \mathrm{p}=0.018)$ and urinary $\mathrm{Ca} /$ creatinine ratio $(\mathrm{rS}-0.51, \mathrm{p}=0.01)$. Other serum parameters were found in the normal range, but PTH was slightly increased in four patients (cases 4,13,14, 24), osteocalcin in four (cases 10, 11, $14,15)$, phosphorus in one ${ }^{21}$ and ALP in two, ${ }^{7,12}$ while creatinine and ALP were slightly reduced in cases 12

Table 2. Serum biochemical data of patients with differentiated thyroid carcinoma studied at baseline at the time of the rhTSH test.

\begin{tabular}{|c|c|c|c|c|c|c|c|c|}
\hline & $\begin{array}{c}\text { OPG } \\
\mathrm{pmol} / \mathrm{l}\end{array}$ & $\begin{array}{c}\text { RANK-L } \\
\text { pmol/l }\end{array}$ & $\begin{array}{c}\text { PTH } \\
\text { ng/l }\end{array}$ & $\begin{array}{c}\text { Osteocalcin } \\
\mu \mathrm{g} / \mathrm{l}\end{array}$ & $\begin{array}{c}\mathrm{Ca} \\
\mathrm{mmol} / \mathrm{l}\end{array}$ & $\begin{array}{c}\mathrm{P} \\
\mathrm{mmol} / \mathrm{l}\end{array}$ & $\begin{array}{c}\text { Creatinine } \\
\mu \mathrm{mol} / \mathrm{l}\end{array}$ & $\begin{array}{r}\text { ALP } \\
\mathbf{U} / \mathbf{l}\end{array}$ \\
\hline \multicolumn{9}{|c|}{ Pre-menopausal women $(n=7)$} \\
\hline median & 2.5 & 0.34 & 43 & 4.0 & 2.4 & 1.0 & 70.8 & 185 \\
\hline $25 \%$ percentile & 2.2 & 0.26 & 38 & 3.3 & 2.3 & 0.9 & 70.8 & 141 \\
\hline $75 \%$ percentile & 4.1 & 0.78 & 65 & 5.1 & 2.5 & 1.1 & 70.8 & 296 \\
\hline \multicolumn{9}{|c|}{ Post-menopausal women $(n=10)$} \\
\hline median & 2.2 & 0.19 & 47 & 4.4 & 2.5 & 1.1 & 62.0 & 193 \\
\hline $25 \%$ percentile & 1.3 & 0.10 & 37 & 2.7 & 2.4 & 0.9 & 53.1 & 158 \\
\hline $75 \%$ percentile & 2.7 & 0.29 & 61 & 8.1 & 2.5 & 1.2 & 88.5 & 217 \\
\hline \multicolumn{9}{|l|}{ Males $(n=7)$} \\
\hline median & 1.9 & 0.31 & 44 & 2.9 & 2.3 & 1.0 & 79.6 & 182 \\
\hline $25 \%$ percentile & 1.4 & 0.22 & 37 & 2.2 & 2.1 & 0.9 & 66.4 & 131 \\
\hline $75 \%$ percentile & 2.8 & 0.39 & 65 & 4.2 & 2.7 & 1.6 & 110.6 & 188 \\
\hline
\end{tabular}

(See Assay section in Materials and Methods for normal ranges) 
and 3 , respectively (Table 2). Urinary calcium excretion was increased in 24-h samples in cases 7, 15 and 22 , and reduced in case 21 ; however, when corrected for creatinine excretion in spot samples, only case 8 showed an abnormal value (Table 3). Urinary HP and cross-links were increased in several post-menopausal subjects. More than one of these parameters of bone resorption were simultaneously increased in four subjects (cases 9, 12, 14 and 15) (Table 3). A decrease in BMD was found at the spinal and total-hip level in $48 \%$ and $43 \%$ of subjects, respectively. In addition, spinal osteoporosis was found in six subjects (cases $1,8,9,1214$ and 15) and total-hip osteoporosis in only one (case 9) (Table 4).

Table 3. Pertinent urine biochemical data of DTC patients studied at baseline of the rhTSH test. The ratios between the urinary excretion of calcium, hydroxyproline (HP), pyridinoline (PD) and deoxypiridinoline (DPD) and that of creatinine were calculated on morning diluted urine collected according to methodology described in the Materials and Methods section.

\begin{tabular}{|c|c|c|c|c|c|}
\hline & $\begin{array}{l}24 \mathrm{~h} \mathrm{U}-\mathrm{Ca} \\
\mathrm{mmol} / 24 \mathrm{~h}\end{array}$ & $\begin{array}{c}\text { Ca/creatinine } \\
\text { nmol/nmol }\end{array}$ & $\begin{array}{c}\text { HP/creatinine } \\
\text { nmol/nmol }\end{array}$ & $\begin{array}{c}\text { PD/creatinine } \\
\text { nmol/nmol }\end{array}$ & $\begin{array}{c}\text { DPD/creatinine } \\
\mathrm{nmol} / \mathrm{nmol}\end{array}$ \\
\hline \multicolumn{6}{|c|}{ Pre-menopausal women $(n=7)$} \\
\hline median & 4.1 & 0.08 & 19.4 & 45.7 & 10.0 \\
\hline $25 \%$ percentile & 2.7 & 0.04 & 17.6 & 36.2 & 8.5 \\
\hline $75 \%$ percentile & 6.7 & 0.14 & 23.2 & 53.6 & 14.2 \\
\hline \multicolumn{6}{|c|}{ Post-menopausal women $(n=10)$} \\
\hline median & 3.5 & 0.09 & 22.1 & 55.9 & 11.6 \\
\hline $25 \%$ percentile & 2.5 & 0.06 & 18.1 & 38.3 & 9.4 \\
\hline $75 \%$ percentile & 6.4 & 0.14 & 27.7 & 71.6 & 17.1 \\
\hline \multicolumn{6}{|l|}{ Males $(\mathbf{n}=7)$} \\
\hline median & 4.5 & 0.04 & 16.5 & 28.2 & 5.5 \\
\hline $25 \%$ percentile & 2.6 & 0.03 & 15.9 & 26.0 & 5.0 \\
\hline $75 \%$ percentile & 7.1 & 0.12 & 20.0 & 32.5 & 6.7 \\
\hline
\end{tabular}

See Assay section in Material and Methods for normal ranges.

Table 4. Bone mass density evaluated at the spinal (L2-L4) and total-hip sites by DXA equipment. The SD from the peak bone mass (T score) and the age- and sex-matched controls of instrument ( $\mathrm{Z}$ score) are reported.

\begin{tabular}{|c|c|c|c|c|c|c|}
\hline \multirow[b]{2}{*}{ Case } & \multicolumn{3}{|c|}{ Spinal BMD } & \multicolumn{3}{|c|}{ Total hip BMD } \\
\hline & $\begin{array}{l}\text { BMD } \\
\mathrm{g} / \mathrm{cm}^{2}\end{array}$ & T score & $Z$ score & $\begin{array}{l}\text { BMD } \\
\mathrm{g} / \mathrm{cm}^{2}\end{array}$ & T score & Z score \\
\hline \multicolumn{7}{|c|}{ Pre-menopausal women $(\mathrm{n}=6)$} \\
\hline median & 1.087 & -0.8 & -0.8 & 0.993 & 0.2 & 0.0 \\
\hline $25 \%$ percentile & 0.820 & -2.5 & -2.3 & 0.836 & -1.2 & -1.1 \\
\hline $75 \%$ percentile & 1.218 & 1.0 & 0.5 & 1.098 & 1.0 & 1.5 \\
\hline \multicolumn{7}{|c|}{ Post-menopausal women $(\mathrm{n}=10)$} \\
\hline median & 0.827 & -2.2 & -0.5 & 0.743 & -1.5 & -0.6 \\
\hline $25 \%$ percentile & 0.788 & -2.7 & -1.2 & 0.643 & -2.2 & -1.5 \\
\hline $75 \%$ percentile & 1.009 & -1.1 & 0.1 & 0.853 & -0.9 & 0.4 \\
\hline \multicolumn{7}{|l|}{ Males $(n=6)$} \\
\hline median & 1.138 & 0.2 & 0.0 & 0.927 & -0.9 & -0.4 \\
\hline $25 \%$ percentile & 0.901 & -1.3 & -1.5 & 0.810 & -1.5 & -1.0 \\
\hline $75 \%$ percentile & 1.300 & 2.1 & 1.7 & 1.012 & -0.1 & 0.5 \\
\hline
\end{tabular}


Free T3 and FT4 concentrations were unaffected by rhTSH administration (data not reported). Twentyfour hours after the second administration of rhTSH, the level of serum TSH was significantly increased (median $192.2 \mathrm{IU} / \mathrm{l} ; 217 \pm 20.9 \mathrm{mIU} / \mathrm{l} ; \mathrm{p}<0.001$ vs baseline). After rhTSH, all but three patients had undetectable $\mathrm{Tg}$ levels. Tg detectable levels were noted in cases $14(1.5 \mu \mathrm{g} / \mathrm{l}), 16(0.9 \mu \mathrm{g} / \mathrm{l})$ and $18(1.1$ $\mu \mathrm{g} / \mathrm{l})$.

Figure 1 shows the values of OPG and RANK-L after rhTSH administration. No significant variation in OPG and RANK-L was found following rhTSH administration. No correlation was observed between the peak value of TSH on day 3 and the maximal percentage change in OPG (median 109.0\%; 126 $\pm 14.2 \%$ ) and RANK-L (median $80.0 \% ; 175.8 \pm 58.9 \%$ ) attained after rhTSH administration. A slight increase in urinary cross-links was observed during rhTSH testing (Figure 2), but no correlation between TSH peak and maximal percentage change in $\mathrm{PD} /$ creatinine (median $131 \% ; 124 \pm 11.2 \%$ ) or DPD/creatinine $(127 \% ; 131.5 \pm 13.1 \%)$ ratio was observed.

\section{DISCUSSION}

It has been shown that besides the thyroid many tissues express TSH receptors (TSHRs). ${ }^{29}$ Therefore, several biological roles for TSH have been speculated. In recent years, TSH has been considered to exert extra-thyroid effects, such as the production of nitric oxide in vivo ${ }^{30}$ and of cyclic adenosine monophosphate in vitro. ${ }^{31} \mathrm{~A}$ recent paper has also suggested that rhTSH may stimulate thyroid angiogenesis in vivo. ${ }^{32}$ Moreover, it has been shown that interleukin-6 (IL-6) release from human abdominal adipose cells in culture is regulated by $\mathrm{TSH} .{ }^{33}$ Furthermore, rhTSH increases serum IL-6 response in thyroidectomized patients, indicating an extra-thyroid site of TSH action. ${ }^{33}$

It has also been claimed that TSH may exert a critical effect on components of skeletal remodelling by interacting with a specific receptor expressed on osteoblast and osteoclast precursors. ${ }^{22}$ In vitro, TSH promotes osteoclastogenesis, while in experimental animals, reduced expression of the TSH receptor leads to the development of osteoporosis. These results suggest that TSH could have an inhibitory effect on bone resorption, ${ }^{22}$ though its physiological relevance
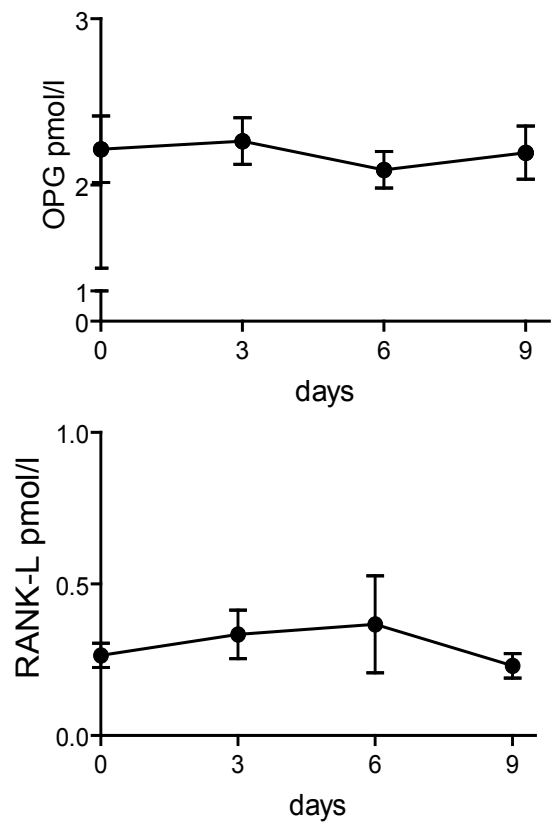

Figure 1. Time-course of serum OPG and RANK-L before and after rhTSH administration.
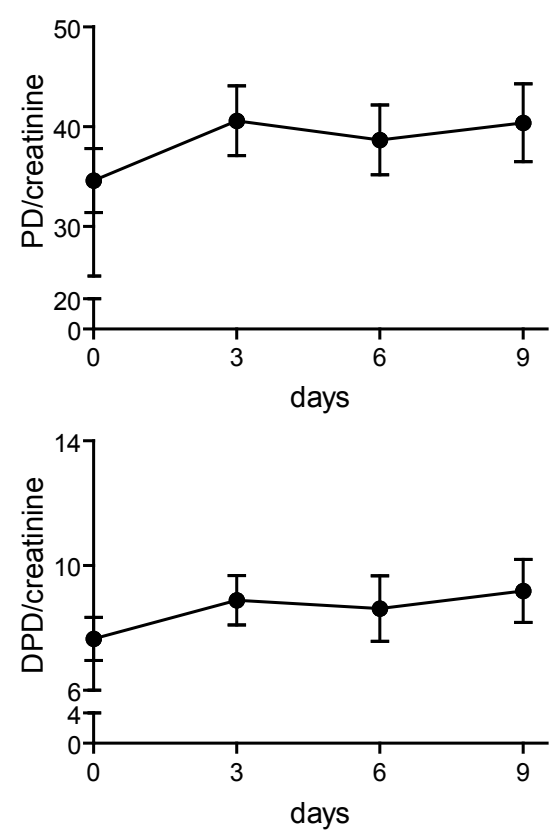

Figure 2. Time-course of urinary cross-links, $\mathrm{PD} /$ creatinine and $\mathrm{DPD} /$ creatinine ratios evaluated in $18 \mathrm{DTC}$ subjects before and after rhTSH administration.

seems to be slight because of the weak expression of the TSH receptor on human osteoblasts. ${ }^{34}$ However, it is possible that extreme conditions, such as the TSH increase in hypothyroidism or TSH suppression in 
hyperthyroidism, may activate additional regulatory pathways of bone remodelling which are normally not operative. The link between the pituitary-thyroid axis and bone metabolism is not fully understood, as abnormal serum thyroid hormone levels act as confounding factors. Indeed, it is well known that thyroid hormones have a direct effect on bone cells through specific receptor binding ${ }^{35}$ and subsequent enhancement of mRNA expression, ${ }^{36}$ thereby producing the generally acknowledged feature of bone loss and osteoporosis. ${ }^{16}$

Whether the link between the pituitary-thyroid axis and bone remodelling involves a TSH action on the OPG/RANK/RANK-L system is a controversial issue. Alterations in serum OPG levels have been described in both hyper- and hypothyroidism ${ }^{17,18}$ but, in our experience, OPG and RANK-L levels are comparable in patients with a history of DTC and suppressed endogenous TSH on L-T4, and in those with a history of non-malignant thyroid diseases. ${ }^{37}$ By contrast, other authors have recently reported an increase in OPG and a decrease in RANK-L levels in DTC patients in comparison with age-matched normal subjects. ${ }^{19}$

In our study, rhTSH was administered both to subjects with slight hyperthyroxinemia and to those in whom L-T4 had previously been reduced for diagnostic purposes. ${ }^{24}$ This procedure was intended to sensitize the Tg response to rhTSH according to a protocol currently under evaluation. However, a significant increase in serum TSH was seen following rhTSH administration without any change in OPG. This finding is in agreement with that reported by Mazziotti et al. ${ }^{23}$ In addition, our study documents no significant rhTSH-stimulated variation in soluble RANK-L levels. No correlation was observed between the peak value of TSH on day 3 and the maximal percentage change in OPG and RANK-L after rhTSH administration. Therefore, our data do not support an acute direct effect on OPG and RANK-L in patients with a history of DTC on L-T4 regimen, thus confirming the view that the inhibitory role of TSH on osteoclastogenis is achieved through mechanisms that do not involve osteoblast-osteoclast cross-talk via the OPG/RANK/RANKL system. Our results are in agreement with the recent observation that $\mathrm{TNF} \alpha$ is the critical cytokine in mediating the downstream anti-resorption effects of TSH on the skeleton. ${ }^{38}$

There is a substantial difference between Mazziotti's study ${ }^{23}$ and ours in the sequential profile of the biochemical markers of bone metabolism observed during rhTSH administration. These authors found that the acute increase in serum TSH levels was accompanied by a reversible decrease in serum Cterminal cross-linking telopeptide of type I collagen (cross-laps) in postmenopausal thyroidectomized women on L-T4 suppressive therapy. In our study, however, we did not observe an analogous change in the urinary excretion of DPD during rhTSH administration. As discussed by Mazziotti et al, ${ }^{23}$ the temporal relationship between the increase in TSH and the transient decrease in cross-laps would suggest that bone resorption is affected by TSH itself. However, the potential change in glucose handling due to the fasting condition and TSH-insulin interactions at the receptor level in Mazziotti's model might have contributed to the decrease observed in cross-laps, as the marker is strongly affected by feeding. ${ }^{39}$ The absence of a fall in cross-laps in premenopausal women ${ }^{23}$ as well as the absence of significant changes in DPD excretion, indirectly supports the view that the observed drop in cross-laps might have a nonosseous origin. The absence of acute changes in the biochemical markers of osteoclast activity in our study do not rule out a long-term skeletal effect of TSH in humans. Indeed, while collagen degradation products reflect osteoclast activity, they might not be sensitive to the sudden change in osteoclastogenesis induced by the sharp increase of TSH concentration in the plasma.

In conclusion, this study confirms that OPG is not involved in the skeletal effect of TSH, and also excludes any involvement of RANKL or of the OPGto-RANKL ratio. While the skeletal effects of TSH in humans require further analysis, this study indicates that any changes in serum OPG observed in acute alterations of thyroid function should be regarded as compensatory attempts to enhance the activation frequency of bone remodelling via mechanisms independent of the OPG/RANK/RANKL system. 


\section{REFERENCES}

1. Simonet WS, Lacey DL, Dunstan CR, et al, 1997 Osteoprotegerin: a novel secreted protein involved in the regulation of bone density. Cell 89: 309-319.

2. Yasuda H, Shima N, Nakagawa N, et al, 1998 Identity of osteoclastogenesis inhibitory factor (OCIF) and osteoprotegerin: a mechanism by which OPG/OCIF inhibits osteoclastogenesis in vitro. Endocrinology 139: 13291337.

3. Wong BR, Josien R, Lee SY, et al, 1997 TRANCE (Tumor Necrosis Factor (TNF)-related activation-induced cytokine), a new TNF family member predominantly expressed in T cells, is a dendritic cell-specific survival factor. J Exp Med 186: 2075-2080.

4. Lacey DL, Timms E, Tan HL, et al, 1998 Osteoprotegerin ligand is a cytokine that regulates osteoclast differentiation and activation. Cell 93: 165-176.

5. Yun TJ, Chaudhary PM, Shu GL, et al, 1998 OPG/FDCR-1 a TNF receptor family member, is expressed in lymphoid cells and is up-regulated by ligating CD40. J Immunol 161: 6113-6121.

6. Hofbauer LC, Kluger S, Kuhne CA, et al, 2002 Detection and characterization of RANK ligand and osteoprotegerin in the thyroid gland. J Cell Biochem 86: 642-650.

7. Yasuda H, Shima N, Nakagawa N, et al, 1998 Osteoclast differentiation factor is a ligand for osteoprotegerin/ osteoclastogenesis-inhibitory factor and is identical to TRANCE/RANKL. Proc Natl Acad Sci USA 95: $3597-$ 3602.

8. Rogers A, Eastell R, 2005 Circulating osteoprotegerin and receptor activator of nuclear factor kappaB ligand: clinical utility in metabolic bone disease assessment. J Clin Endocrinol Metab 90: 6323-6331.

9. Burgess TL, Qian Y, Kaufman S, et al, 1999 The ligand for osteoprotegerin (OPGL) directly activates mature osteoclasts. J Cell Biol 145: 527-538.

10. Fujikawa Y, Sabokbar A, Neale SD, Itonaga I, Torisu T, Athanasou NA, 2001 The effect of macrophage-colony stimulating factor and other humoral factors (interleukin-1, -3, -6 and -11, tumor necrosis factor-alpha, and granulocyte macrophage-colony stimulating factor) on human osteoclast formation from circulating cells. Bone 28: 261-267.

11. Kiechl S, Schett G, Wenning G, et al, 2004 Osteoprotegerin is a risk factor for progressive atherosclerosis and cardiovascular disease. Circulation 109: 175-180.

12. Hofbauer LC, Heufelder AE, 2000 The role of osteoprotegerin and receptor activator of nuclear factor-kB ligand in the pathogenesis and treatment of metabolic bone diseases. J Clin Endocrinol Metab 85: 2355-2363.

13. Hofbauer LC, Neubauer A, Heufelder AE, 2001 Receptor activator of nuclear factor-kB ligand and osteoprotegerin: potential implications for the pathogenesis and treatment of malignant bone diseases. Cancer 92: 460-470.

14. Kong YY, Boyle WJ, Penninger JM, 2000 Osteoprote- gerin ligand: a regulator of immune responses and bone physiology. Immunol Today 21: 495-502.

15. Bekker PJ, Holloway D, Nakanishi A, Arrighu M, Leese PT, Dunstan CR, 2001 The effect of a single dose of osteoprotegerin in post-menopausal women. J Bone Miner Res 14: 518-527.

16. Isaia GC, Roggia C, Gola D, et al, 2000 Bone turnover in hyperthyroidism before and after thyrostatic management. J Endocrinol Invest 23: 727-731.

17. Amato G, Mazziotti G, Sorvillo F, et al, 2004 High serum osteoprotegerin levels in patients with hyperthyroidism: effect of medical treatment. Bone 35: 785-791.

18. Guang-da X, Hui-ling S, Zhi-song C, Lin-shuang Z, 2005 Changes in plasma concentrations of osteoprotegerin before and after levothyroxine replacement therapy in hypothyroid patients. J Clin Endocrinol Metab 90: 57655768.

19. Mikosch P, Igerc I, Kudlacek S, et al, 2006 Receptor activator of nuclear factor $\chi \mathrm{B}$ ligand and osteoprotegerin in men with thyroid cancer. Eur J Clinical Invest 36: 566573.

20. Indridason OS, Franzson L, Sigurdsson G, 2005 Serum osteoprotegerin and its relationship with bone mineral density and markers of bone turnover. Osteoporos Inter 16: 417-423.

21. Ziegler S, Niessner A, Richter B, et al, 2005 Endurance running acutely raises plasma osteoprotegerin and lowers plasma receptor activator of nuclear $\chi \mathrm{B}$ ligand. Metabolism 54: 935-938.

22. Abe E, Marians RC, Yu W, et al, 2003 TSH is a negative regulator of skeletal remodelling. Cell 115: 151-162.

23. Mazziotti G, Sorvillo F, Piscopo M, et al, 2005 Recombinant human TSH modulates in vivo C-telopeptides of type- 1 collagen and bone alkaline phosphatase, but not osteoprotegerin in postmenopausal women monitored for differentiated thyroid carcinoma. J Bone Miner Res 20: 480-486.

24. Giusti M, Cappi C, Augeri C, Cavallero D, Molinari E, Minuto F, 2004 Recombinant human TSH (rh-TSH) testing after short-term L-thyroxine (L-T4) reduction: a sensitising test to confirm a disease free state in papillary thyroid carcinoma (PTC). $12^{\text {th }}$ International Congress of Endocrinology August 31-September 4. Abstracts book pp. 259-260.

25. Spencer CA, Bergoglio LM, Kazarosyan M, Fatemi S, LoPresti JS, 2005 Clinical impact of thyroglobulin (Tg) and $\mathrm{Tg}$ autoantibody method differences on the management of patients with differentiated thyroid carcinoma. J Clin Endocrinol Metab 90: 5566-5575.

26. Duntas LH, Tsakalakos N, Grab-Duntas B, Kalarritou M, Papadodima E, 2003 The use of recombinant human (Thyrogen) in the diagnosis and treatment of thyroid cancer. Hormones 16: 169-174.

27. Torlontano M, Attard M, Crocetti U, et al, 2004 Follow-up of low risk patients with papillary thyroid cancer: role of neck ultrasonography in detecting lymph node 
metastases. J Clin Endocrinol Metab 89: 3402-3407.

28. Faulkner KG 2001 Clinical use of bone densitometry. In Marcus R, Feldman D, Kelsey J (eds) Osteoporosis, Academic Press, San Diego-London, vol 2; pp, 433-458.

29. Davies TF, Marians R, Latif R, 2002 The TSH receptor reveals itself. J Clin Invest 110: 161-164.

30. Giusti M, Valenti S, Guazzini B, et al, 2003 Circulating nitric oxide is modulated by recombinant human TSH administration during monitoring of thyroid cancer remnant. J Endocrinol Invest 26: 1192-1197.

31. Selliti DF, Dennison D, Akamizu T, Doi SQ, Kohn LD, Koshiyama H, 2000 Thyrotropin regulation of cyclic adenosine monophosphate production in human coronary artery smooth muscle cells. Thyroid 10: 219-225.

32. Klein M, Brunaud L, Muresan M, et al, 2006 Recombinant human thyrotropin stimulates thyroid angiogenesis in vivo. Thyroid 16: 531-536.

33. Antunes TT, Gagnon A, Chen B, Pacini F, Smith TJ, Sorisky A, 2006 Interleukine-6 release from human abdominal adipose cells is regulated by thyroid-stimulating hormone: effect of adipocyte differentiation and anatomic depot. Am J Physiol Endocrinol Metab 290: 1140-1144.
34. Tsaj JA, Janson A, Bucht E, et al, 2004 Weak evidence of thyrotropin receptors in primary cultures of human osteoblast-like cells. Calcif Tissue Int 74: 486-491.

35. Abu EO, Bord S, Horner A, Chatterjee VK, Compston JE, 1997 The expression of thyroid hormone receptor in human bone. Bone 21: 137-142.

36. Abu EO, Horner A, Teti A, Chatterjee VK, Compston JE, 2000 The localization of thyroid hormone receptor mRNAs in human bone. Thyroid 10: 287-293.

37. Giusti M, Cecoli F, Fazzuoli L, et al, 2006 Serum osteoprotegerin and soluble receptor activator of nuclear factor-kB ligand (RANK-L) levels in patients with a history of differentiated thyroid carcinoma: a case-controlled cohort study. Metabolism 56: 699-707.

38. Hase H, Ando T, Eldeiry L, et al, 2006 TNF $\alpha$ mediates the skeletal effects of thyroid-stimulating hormone. Proc Natl Acad Sci U S A 103: 12849-12854.

39. Qvist P, Christgau S, Pedersen BJ, Schlemmer A, Christiansen C, 2002 Circadian variation in the serum concentration of C-terminal telopeptide of type I collagen (serum CTx): effects of gender, age, menopausal status, posture, daylight, serum cortisol, and fasting. Bone 31: 57-61. 